\title{
Effect of fluorine implantation dose on boron thermal diffusion in silicon
}

\author{
H. A. W. El Mubarek, J. M Bonar, G. D. Dilliway, and P. Ashburn \\ School of Electronics \& Computer Science, University of Southampton, Southampton, United Kingdom \\ M. Karunaratne and A. F. Willoughby \\ Department of Materials, University of Southampton, Southampton, United Kingdom \\ Y. Wang and P. L. F. Hemment \\ School of Electrical \& Electronic Engineering, University of Surrey, Guildford, United Kingdom \\ R. Price and J. Zhang \\ Department of Physics, Imperial College, University of London, London, United Kingdom \\ P. Ward \\ ST Microelectronics, Catania, Italy
}

(Received 23 April 2004; accepted 19 July 2004)

This paper investigates how the thermal diffusion of boron in silicon is influenced by a high energy fluorine implant with a dose in the range $5 \times 10^{14}-2.3 \times 10^{15} \mathrm{~cm}^{-2}$. Secondary Ion Mass Spectroscopy (SIMS) profiles of boron marker layers are presented for different fluorine doses and compared with fluorine profiles to establish the conditions under which thermal boron diffusion is suppressed. The (SIMS) profiles show significantly reduced boron thermal diffusion above a critical $\mathrm{F}^{+}$dose of $0.9-1.4 \times 10^{15} \mathrm{~cm}^{-2}$. Fitting of the measured boron profiles gives suppressions of the boron thermal diffusion coefficient by factors of 1.9 and 3.7 for $\mathrm{F}^{+}$implantation doses of 1.4 $\times 10^{15}$ and $2.3 \times 10^{15} \mathrm{~cm}^{-2}$, respectively. The suppression of boron thermal diffusion above the critical fluorine dose correlates with the appearance of a shallow fluorine peak on the (SIMS) profile in the vicinity of the boron marker layer. This shallow fluorine peak is present in samples with and without boron marker layers, and hence it is not due to a chemical interaction between the boron and the fluorine. Analysis of the (SIMS) profiles and cross-section Transmission Electron Microscope micrographs suggests that it is due to the trapping of fluorine at vacancy-fluorine clusters, and that the suppression of the boron thermal diffusion is due to the effect of the clusters in suppressing the interstitial concentration in the vicinity of the boron profile. () 2004 American Institute of Physics. [DOI: $10.1063 / 1.1790063$ ]

\section{INTRODUCTION}

Over the past few years there has been considerable interest in the effect of fluorine on boron diffusion in silicon. ${ }^{1-18}$ This research has been motivated by the requirement in advanced CMOS technologies to minimize boron diffusion for the formation of shallow source/drain junctions and sharply defined halo profiles. ${ }^{19,20}$ The minimization of boron diffusion is also important in bipolar transistors, where boron diffusion limits the achievable base width and hence the value of cutoff frequency that can be obtained. ${ }^{21}$ The suppression of boron diffusion is difficult to achieve in practice because of both boron thermal diffusion and boron transient enhanced diffusion due to damage created during ion implantation. $^{22}$

Work on the effects of fluorine from a $\mathrm{BF}_{2}^{+}$implant showed that shallower junctions could be obtained when $\mathrm{BF}_{2}^{+}$was implanted instead of $\mathrm{B}^{+} .1,7,8$ In later work $^{2-6,9-15,17,18}$ fluorine was implanted separately to the boron to characterize the effect of the fluorine on boron diffusion. This work showed that the fluorine implant reduced boron transient enhanced diffusion ${ }^{2-5,9,11,13,14,16-18}$ and increased boron activity. ${ }^{2}$ However, there have also been contradictory reports in the literature, which showed that fluorine implants had little or no effect on boron transient enhanced diffusion ${ }^{10}$ and that fluorine enhanced boron diffusion in preamorphized silicon ${ }^{6}$ using a silicon implant. ${ }^{15} \mathrm{Re}-$ cently El Mubarek and Ashburn ${ }^{18}$ showed that a deep $\mathrm{F}^{+}$ implant significantly reduced boron thermal diffusion, as well as eliminating transient enhanced diffusion.

Several alternative mechanisms have been proposed to explain the effect of the fluorine on both boron transient enhanced diffusion and boron thermal diffusion in silicon. ${ }^{1-18} \mathrm{~A}$ chemical interaction between boron and fluorine has been proposed to explain the suppression of boron transient enhanced diffusion by fluorine, ${ }^{4,9,11,14,16}$ in which the fluorine combines with interstitial boron reducing its mobility ${ }^{4,11,14,16}$ or reduces the probability of formation of a boron interstitial pair. ${ }^{9,11}$ Alternatively, the formation of vacancy-fluorine complexes has been proposed, ${ }^{13,17,18,23-26}$ which act as a barrier for boron diffusion, ${ }^{13}$ or suppress the interstitial concentration and hence reduce boron transient enhanced diffusion ${ }^{17}$ and thermal diffusion. ${ }^{18}$ Finally the interaction of fluorine with silicon interstitials has been widely proposed as a mechanism of suppressing boron transient enhanced diffusion. ${ }^{2,4-10,18}$

In this paper, experiments are performed to investigate how the fluorine implantation dose influences the thermal diffusion of boron marker layers in silicon. Boron secondary 
ion mass spectroscopy (SIMS) profiles are studied for different fluorine implantation doses and compared with the corresponding fluorine profiles. It is shown that a critical fluorine dose exists, above which the fluorine suppresses boron thermal diffusion and below which it does not and that this critical fluorine dose correlates with the appearance of a shallow fluorine peak on the fluorine SIMS profile in the vicinity of the boron marker layer. Explanations are proposed for the origin of this shallow fluorine peak and its effect on boron thermal diffusion.

\section{EXPERIMENTAL PROCEDURE}

Silicon layers with and without a buried boron-doped marker layer were grown on (100) silicon wafers using molecular beam epitaxy at $520{ }^{\circ} \mathrm{C}$ and low pressure chemical vapor deposition at $800^{\circ} \mathrm{C}$, respectively. Samples from the same wafer were then given a $185 \mathrm{keV}$ fluorine implant with a dose in the range $5 \times 10^{14}-2.3 \times 10^{15} \mathrm{~cm}^{-2}$. By comparing boron profiles on $\mathrm{F}^{+}$implanted and unimplanted samples it is therefore possible to unambiguously determine the effect of the fluorine implantation dose on the boron thermal diffusion. The layers were annealed by rapid thermal annealing in nitrogen at $1000{ }^{\circ} \mathrm{C}$ for $30 \mathrm{~s}$. Boron (B11) and fluorine (F19) concentration depth profiles were obtained on all samples by SIMS using a $10 \mathrm{keV} \mathrm{O}+2$ beam. The annealed boron (SIMS) profiles were fitted using the fully coupled diffusion model in the Silvaco Athena simulation program and the diffusion coefficient was extracted from the best fit obtained. The layers were also analyzed by transmission electron microscopy (TEM).

\section{RESULTS}

Figure 1 shows boron SIMS profiles in samples implanted with $\mathrm{F}^{+}$at a dose in the range $5 \times 10^{14}-1.4$ $\times 10^{15} \mathrm{~cm}^{-2}$ and annealed at $1000{ }^{\circ} \mathrm{C}$. For the two lowest $\mathrm{F}^{+}$ doses of $5 \times 10^{14}$ and $9 \times 10^{14} \mathrm{~cm}^{-2}$, there is no evidence of the $\mathrm{F}^{+}$implant reducing the boron thermal diffusion. In contrast, for a $\mathrm{F}^{+}$dose of $1.4 \times 10^{15} \mathrm{~cm}^{-2}$, the fluorine implanted sample shows a significant reduction of boron thermal diffusion compared with the unimplanted sample. Earlier work ${ }^{18}$ on samples implanted with $2.3 \times 10^{15} \mathrm{~cm}^{-2} \mathrm{~F}^{+}$also showed a significant reduction of boron thermal diffusion compared with an unimplanted sample. These results show that fluorine significantly reduces boron thermal diffusion for $\mathrm{F}^{+}$doses at and above $1.4 \times 10^{15} \mathrm{~cm}^{-2}$.

Figure 2 shows a comparison of simulated and measured boron profiles of samples implanted with $\mathrm{F}^{+}$at a dose in the range $5 \times 10^{14}-1.4 \times 10^{15} \mathrm{~cm}^{-2}$ and annealed at $1000^{\circ} \mathrm{C}$ for $30 \mathrm{~s}$. The as-grown boron profile is also included for reference. In all figures the fitted profiles coincide very well with the measured profiles, indicating a good fit. Extracted values of boron thermal diffusion coefficient, normalized to the value of diffusion coefficient of the unimplanted sample $\left(5.9 \times 10^{-14} \mathrm{~cm}^{2} \mathrm{~s}^{-1}\right)$, are summarized in Table I. Also shown is a value for a $2.3 \times 10^{15} \mathrm{~cm}^{-2} \mathrm{~F}^{+}$implant obtained by fitting the profiles in Ref. 18. The results show a decrease in
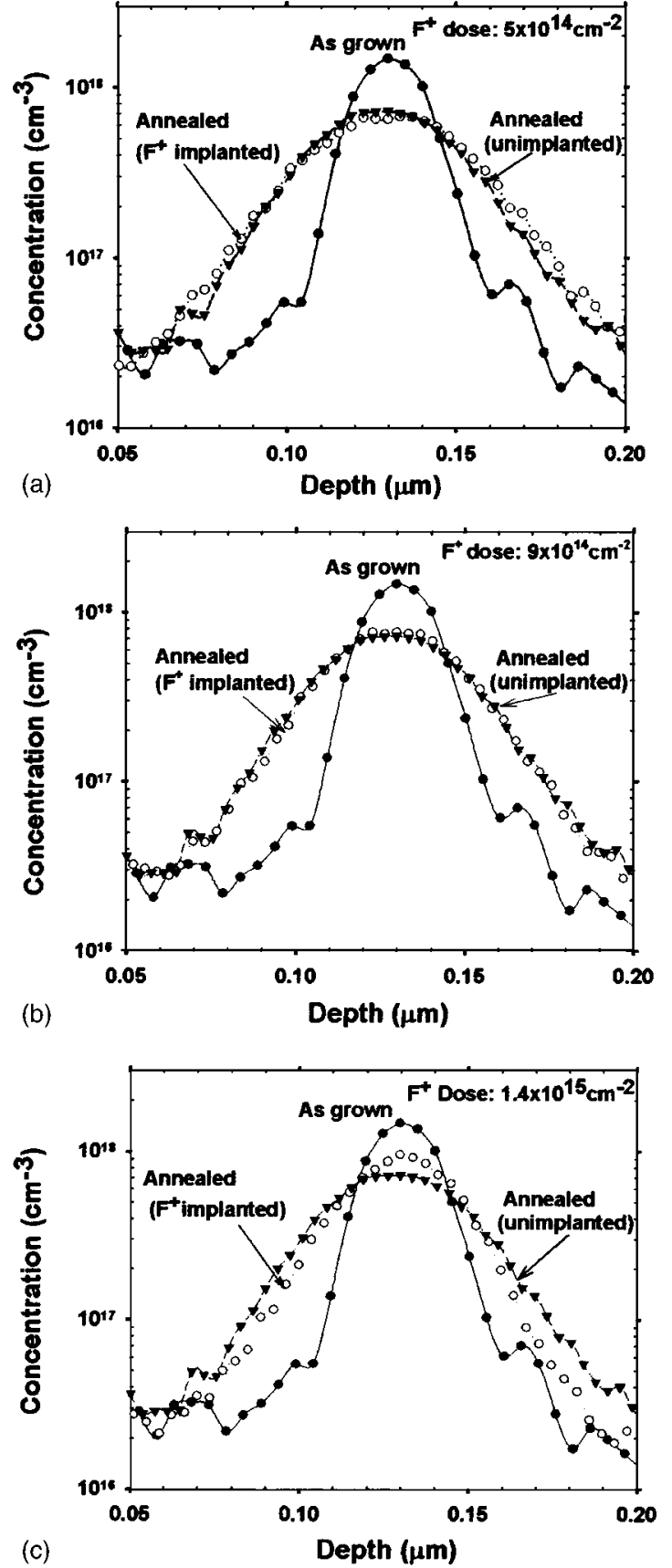

FIG. 1. Boron SIMS profiles in $\mathrm{F}^{+}$implanted and unimplanted samples after an anneal of $30 \mathrm{~s}$ at $1000{ }^{\circ} \mathrm{C}$ in dry $\mathrm{N}_{2}$. An as-grown boron profile is also included for reference. Results are shown for fluorine implantation doses of (a) $5 \times 10^{14} \mathrm{~cm}^{-2}$, (b) $9 \times 10^{14} \mathrm{~cm}^{-2}$, and (c) $1.4 \times 10^{15} \mathrm{~cm}^{-2}$.

the boron diffusion coefficient by factors of 1.9 and 3.7 for samples implanted with $1.4 \times 10^{15}$ and $2.3 \times 10^{15} \mathrm{~cm}^{-2} \mathrm{~F}^{+}$, respectively.

Figure 3 shows fluorine (SIMS) profiles in samples implanted with $\mathrm{F}^{+}$at a dose in the range $5 \times 10^{14}-1.4$ $\times 10^{15} \mathrm{~cm}^{-2}$ and annealed at $1000{ }^{\circ} \mathrm{C}$. For all the implanted doses the as-implanted fluorine profile is approximately Gaussian with an implantation range of $0.41 \mu \mathrm{m}$. For the lowest fluorine implantation dose of $5 \times 10^{14} \mathrm{~cm}^{-2}$, negligible fluorine is present (SIMS background level) in the vicinity of the boron profile after anneal. The majority of the fluorine is located in a broad double peak at a depth corre- 

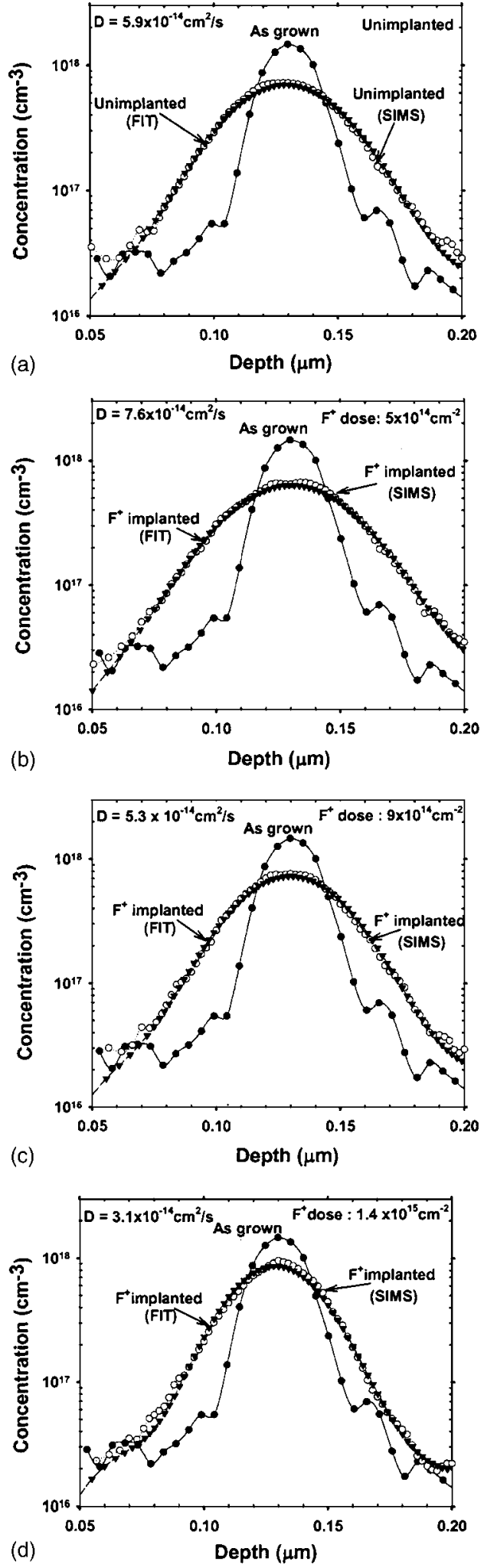

FIG. 2. Simulated and measured boron profiles after an anneal of $30 \mathrm{~s}$ at $1000{ }^{\circ} \mathrm{C}$ in dry $\mathrm{N}_{2}$ and for reference an as-grown boron profile; (a) unimplanted sample, and samples implanted with $\mathrm{F}^{+}$doses: (b) $5 \times 10^{14} \mathrm{~cm}^{-2}$, (c) $9 \times 10^{14} \mathrm{~cm}^{-2}$, (d) $1.4 \times 10^{15} \mathrm{~cm}^{-2}$, and (e) $2.3 \times 10^{15} \mathrm{~cm}^{-2}$.

sponding approximately with the range of the fluorine implant $(0.41 \mu \mathrm{m})$ and extending from about 0.3 to $0.64 \mu \mathrm{m}$. For a fluorine implantation dose of $9 \times 10^{14} \mathrm{~cm}^{-2}$ negligible fluorine is again visible in the vicinity of the boron profile, but a small shoulder can be seen on the surface side of the
TABLE I. Summary of values of normalized boron diffusion coefficient for unimplanted samples and samples implanted with $\mathrm{F}^{+}$doses $5 \times 10^{14}-2.3$ $\times 10^{15} \mathrm{~cm}^{-2}$. Values are normalized to the diffusion coefficient of 5.9 $\times 10^{-14} \mathrm{~cm}^{-2} \mathrm{~s}^{-1}$ for the unimplanted sample.

\begin{tabular}{cc}
\hline \hline $\mathrm{F}^{+}$Implant dose $\mathrm{cm}^{-2}$ & Normalized boron diffusion coefficient \\
\hline Unimplanted & 1 \\
$5 \times 10^{14}$ & 1.3 \\
$9 \times 10^{14}$ & 0.90 \\
$1.4 \times 10^{15}$ & 0.53 \\
$2.3 \times 10^{15}$ & 0.27 \\
\hline \hline
\end{tabular}

deep fluorine peak between about 0.22 and $0.28 \mu \mathrm{m}$. This shoulder was not present for the lower fluorine dose of 5 $\times 10^{14} \mathrm{~cm}^{-2}$ in Fig. 3(a). For the highest fluorine dose of $1.4 \times 10^{15} \mathrm{~cm}^{-2}$, an additional shallow, fluorine peak can be clearly seen in the vicinity of the boron marker layer, extending from about 0.07 to $0.22 \mu \mathrm{m}$. The shape of this shallow fluorine peak is complex and comprises two small ripples at depths of 0.16 and $0.18 \mu \mathrm{m}$. A substantial shoulder can also be seen at a similar depth as the shoulder seen in Fig. 3(b) $(\approx 0.22-0.28 \mu \mathrm{m})$.

Figure 4 shows a comparison of fluorine SIMS profiles in samples with and without a boron marker layer after a fluorine implant in the range $5 \times 10^{14}-2.3 \times 10^{15} \mathrm{~cm}^{-2}$ and annealed at $1000{ }^{\circ} \mathrm{C}$. The corresponding as-implanted fluorine profiles are also shown for reference. The fluorine profiles in the samples without the boron marker layer show the same overall trends as those with the boron marker layer. For all fluorine doses, a broad fluorine peak is seen at a depth corresponding approximately with the range of the fluorine implant. For the lowest $\mathrm{F}^{+}$dose of $5 \times 10^{14} \mathrm{~cm}^{-2}$, there is negligible fluorine in the vicinity of the boron profile. For a fluorine dose of $9 \times 10^{14} \mathrm{~cm}^{-2}$, there is again negligible fluorine in the vicinity of the boron profile, but a shoulder can be seen between about 0.22 and $0.28 \mu \mathrm{m}$. For the highest doses of $1.4 \times 10^{15}$ and $2.3 \times 10^{15} \mathrm{~cm}^{-2}$, an additional shallow fluorine peak can he seen in the vicinity of the boron profile, extending from 0.07 to $0.22 \mu \mathrm{m}$ and 0.04 to $0.22 \mu \mathrm{m}$, respectively. A substantial shoulder can also be seen, extending from about 0.22 to $0.28 \mu \mathrm{m}$. The shallow fluorine peak in the samples with a boron marker layer shows the presence of ripples, whereas no ripples are present in the samples without the boron marker layer. However, it should be noted that the samples with the boron marker layer were grown using molecular beam epitaxy, whereas the samples without the boron marker layer were grown using low pressure chemical vapor deposition. The small ripples may therefore be an artefact of the growth method, for example, due to the trapping of fluorine at interfaces created by short growth interrupts during the molecular beam epitaxy.

Table II summarizes the integrated fluorine doses in different regions of the profiles before and after anneal for fluorine implanted silicon with boron marker layers. The integrated fluorine doses after implant are in reasonable agreement with the implanted dose. The total fluorine doses after anneal indicate that considerable fluorine is lost during anneal, with less fluorine lost for higher implanted doses. For all implant doses the majority of the fluorine after anneal is 

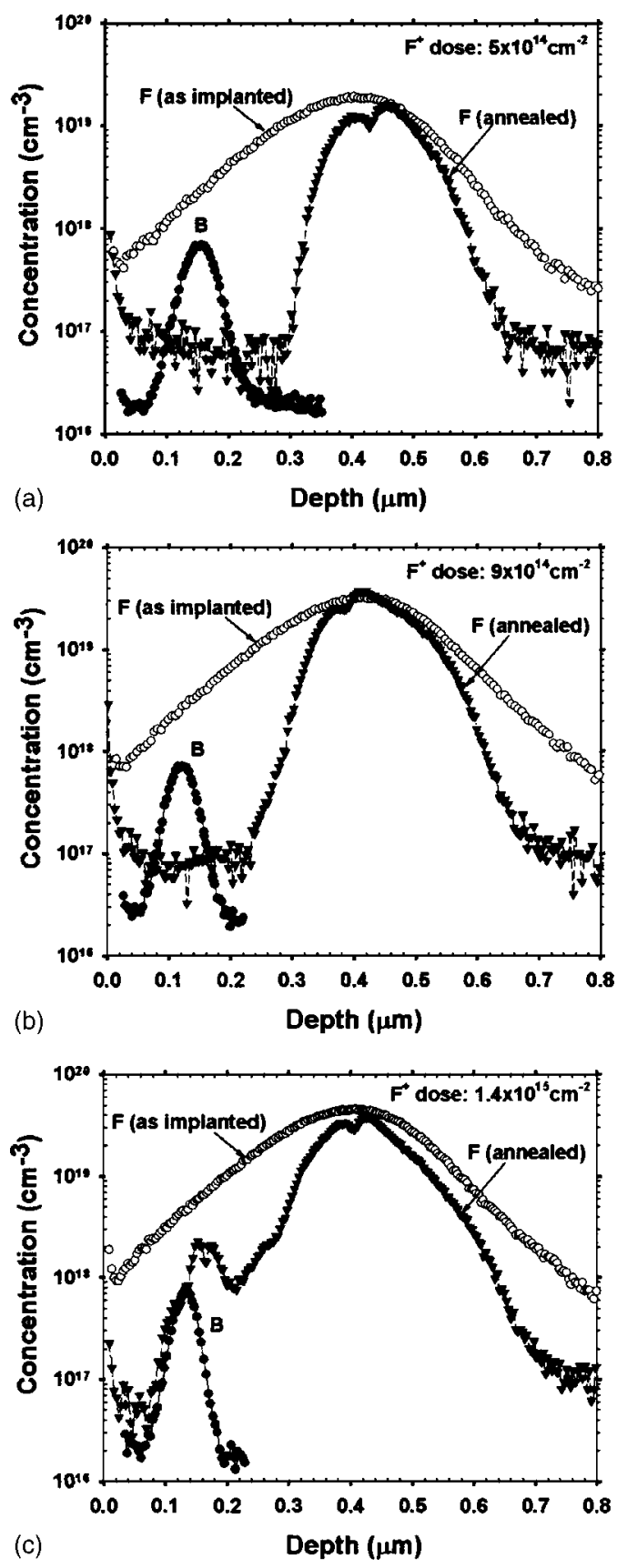

FIG. 3. Fluorine SIMS profiles before and after an anneal of $30 \mathrm{~s}$ at $1000{ }^{\circ} \mathrm{C}$ in dry $\mathrm{N}_{2}$. Boron profiles after anneal are also included for reference. Results are shown for fluorine implantation doses of (a) 5 $\times 10^{14} \mathrm{~cm}^{-2}$, (b) $9 \times 10^{14} \mathrm{~cm}^{-2}$, and (c) $1.4 \times 10^{15} \mathrm{~cm}^{-2}$.

located in the deep fluorine peak, which is defined as extending from 0.28 to $0.70 \mu \mathrm{m}$ (a range encompassing the deep fluorine peak for all doses). For $\mathrm{F}^{+}$doses of $1.4 \times 10^{15}$ and $2.3 \times 10^{15} \mathrm{~cm}^{-2}$, where suppression of boron thermal diffusion is seen, $2.5 \%$ and $5.2 \%$, respectively, of the fluorine resides in the shallow fluorine peak $(0.04-0.22 \mu \mathrm{m}$, and $1.6 \%$ and $2.9 \%$, respectively, resides in the shoulder $(0.22$ to $0.28 \mu \mathrm{m})$.

Figure 5 shows a graph of the peak fluorine concentration in the fluorine peaks and shoulders as a function of $\mathrm{F}^{+}$ implantation dose. Results are shown for samples with and without the boron marker layer. For the shallow fluorine peak, the peak fluorine concentration rises from the SIMS
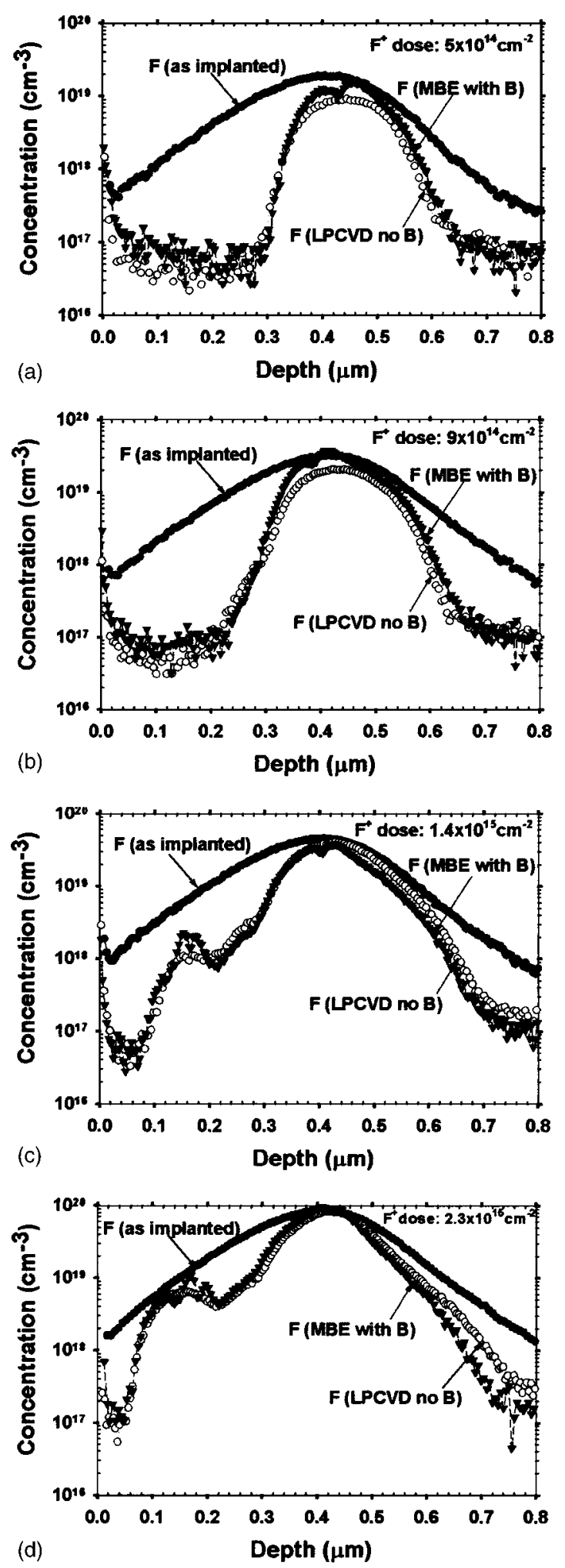

FIG. 4. Fluorine SIMS profiles before and after an anneal of $30 \mathrm{~s}$ at $1000{ }^{\circ} \mathrm{C}$ in dry $\mathrm{N}_{2}$ for samples with and without a boron marker layer. The samples with the boron marker layer were grown using MBE whereas the samples without the boron marker layer were grown using LPCVD. Results are shown for fluorine implantation doses of (a) $5 \times 10^{14} \mathrm{~cm}^{-2}$, (b) 9 $\times 10^{14} \mathrm{~cm}^{-2}$, and (c) $1.4 \times 10^{15} \mathrm{~cm}^{-2}$, and (d) $2.3 \times 10^{15} \mathrm{~cm}^{-2}$.

background level to a value of around $1 \times 10^{18} \mathrm{~cm}^{-3}$ at a $\mathrm{F}^{+}$ implantation dose of $1.4 \times 10^{15} \mathrm{~cm}^{-2}$ and then rises further as the $\mathrm{F}^{+}$dose is increased to $2.3 \times 10^{15} \mathrm{~cm}^{-2}$. For the fluorine shoulder, the peak fluorine concentration rises from the 
TABLE II. Summary of integrated florine doses in different regions of the profiles before and after an anneal of $30 \mathrm{~s}$ at $1000^{\circ} \mathrm{C}$ in dry $\mathrm{N}_{2}$.

\begin{tabular}{|c|c|c|c|c|c|c|c|c|c|}
\hline & & \multicolumn{8}{|c|}{ Fluorine remaining after anneal } \\
\hline \multicolumn{2}{|c|}{ F implant dose $\mathrm{cm}^{-2}$} & \multicolumn{2}{|l|}{ Total } & \multicolumn{2}{|c|}{ Shallow peak $(0.04-0.22 \mu \mathrm{m})$} & \multicolumn{2}{|c|}{ Shoulder $(0.22-0.28 \mu \mathrm{m})$} & \multicolumn{2}{|c|}{ Deep peak $(0.28-0.70 \mu \mathrm{m})$} \\
\hline Implant & SIMS & $\left(\mathrm{cm}^{-2}\right)$ & $(\%)$ & $\left(\mathrm{cm}^{-2}\right)$ & $(\%)$ & $\left(\mathrm{cm}^{-2}\right)$ & $(\%)$ & $\left(\mathrm{cm}^{-2}\right)$ & $(\%)$ \\
\hline $5 \times 10^{14}$ & $5 \times 10^{14}$ & $2.22 \times 10^{14}$ & 44 & $1.4 \times 10^{12}$ & 0.6 & $3.4 \times 10^{11}$ & 0.2 & $2.17 \times 10^{14}$ & 98 \\
\hline $9 \times 10^{14}$ & $8.8 \times 10^{14}$ & $5.55 \times 10^{14}$ & 63 & $1.6 \times 10^{12}$ & 0.3 & $1.8 \times 10^{12}$ & 0.3 & $5.48 \times 10^{14}$ & 99 \\
\hline $1.4 \times 10^{15}$ & $1.2 \times 10^{15}$ & $6.13 \times 10^{14}$ & 51 & $1.5 \times 10^{13}$ & 2.4 & $1.0 \times 10^{13}$ & 1.6 & $5.85 \times 10^{14}$ & 95 \\
\hline $2.3 \times 10^{15}$ & $2.3 \times 10^{15}$ & $1.61 \times 10^{15}$ & 70 & $8.4 \times 10^{13}$ & 5.2 & $4.6 \times 10^{13}$ & 2.9 & $1.45 \times 10^{15}$ & 90 \\
\hline
\end{tabular}

SIMS background to a value of around $1 \times 10^{18} \mathrm{~cm}^{-3}$ at a $\mathrm{F}^{+}$ dose of $9 \times 10^{14} \mathrm{~cm}^{-2}$, and then increases further as the $\mathrm{F}^{+}$ dose is increased to $2.3 \times 10^{15} \mathrm{~cm}^{-2}$. Thus, the trend for the fluorine shoulder is similar to that for the shallow fluorine peak with the difference that the rise in peak fluorine concentration from the SIMS background occurs at a lower fluorine dose. For the deep fluorine peak, a high concentration of fluorine is present for all $\mathrm{F}^{+}$doses and this value rises with increasing $\mathrm{F}^{+}$dose. A similar trend is seen in samples with and without the boron marker layer, though the values of fluorine concentrations tend to be slightly higher in the former samples.

Figure 6(a) shows a light field, cross-section TEM micrograph of a silicon layer with a buried boron marker layer grown by molecular beam epitaxy, implanted with 2.3 $\times 10^{15} \mathrm{~cm}^{-2}$ fluorine and annealed at $1000{ }^{\circ} \mathrm{C}$. A band of defects can be seen extending from a depth of 0.29 to $0.73 \mu \mathrm{m}$ but no defects are seen at depths shallower than $0.29 \mu \mathrm{m}$. A comparison with the SIMS profile in Fig. 4(d) shows that this band of defects corresponds approximately with the position of the deep fluorine peak on the SIMS profile. Figure 6(b) shows a higher magnification micrograph of the band of defects and indicates that the defects consist of dislocation loops with various shapes and sizes ranging from 11 to $96 \mathrm{~nm}$. TEM micographs (not shown here) of samples implanted with $2.3 \times 10^{15} \mathrm{~cm}^{-2} \mathrm{~F}^{+}$show that the layers are crystalline after implant and show no amorphization due to the fluorine implant.

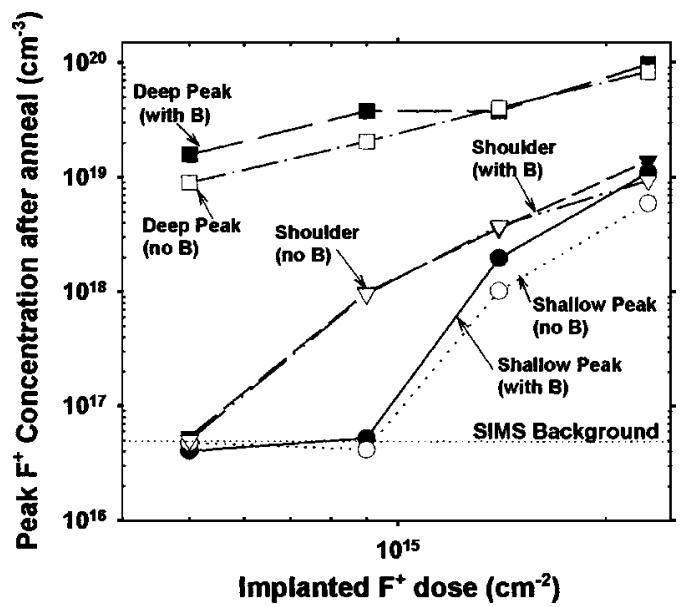

FIG. 5. Fluorine concentrations at depths corresponding to the positions of the shallow fluorine peak the fluorine shoulder and the deep fluorine peak as a function of $\mathrm{F}^{+}$implantation dose. Results are shown for samples with and without a boron marker layer.

\section{DISCUSSION}

The results in Fig. 1 clearly show no reduction of boron thermal diffusion at $\mathrm{F}^{+}$doses of $5 \times 10^{14}$ and $9 \times 10^{14} \mathrm{~cm}^{-2}$, but significant reduction at a $\mathrm{F}^{+}$dose of $1.4 \times 10^{15} \mathrm{~cm}^{-2}$. Furthermore, the results in Fig. 3 show that a shallow fluorine peak is present in the vicinity of the boron marker layer for a $\mathrm{F}^{+}$dose of $1.4 \times 10^{15} \mathrm{~cm}^{-2}$, but is not present for lower doses. Thus there is a correlation between the appearance of the shallow fluorine peak in the vicinity of the boron marker layer and the reduction of boron thermal diffusion. This reduction of boron thermal diffusion occurs above a critical $\mathrm{F}^{+}$ dose of between $9 \times 10^{14}$ and $1.4 \times 10^{15} \mathrm{~cm}^{-2}$.

The shallow fluorine peak in Fig. 3(c) lies at a depth of about $0.07-0.22 \mu \mathrm{m}$, which corresponds to $0.17-0.53 R_{p}$, where $R_{p}$ is the range of the fluorine implant. Simulations of vacancy and interstitial profiles after implantation ${ }^{27,28}$ have predicted a vacancy-rich region extending from the surface to a depth approaching the implantation rang $R_{p}$ and a deeper interstitial-rich region peaking at a depth just beyond $R_{p}$. This indicates that the shallow fluorine peak lies in the vacancy-rich region of the damage profile. Work on the diffusion of fluorine in silicon has shown that fluorine diffuses extremely rapidly in silicon with significant diffusion occurring at temperatures as low as $550{ }^{\circ} \mathrm{C} .{ }^{29}$ Thus on the basis of diffusion alone we would not expect to see much fluorine remaining after the $30 \mathrm{~s}$ anneal at $1000{ }^{\circ} \mathrm{C}$ used in our work. The presence of large fluorine peaks in Fig. 3 after anneal, therefore, suggests that fluorine has been trapped at defects created by the fluorine implant. The TEM micrograph in Fig. 6 shows no evidence of extended defects down to a depth of $0.29 \mu \mathrm{m}$, and hence the trapping of fluorine at the shallow fluorine peak must be due to defects that are too small to resolve by TEM.

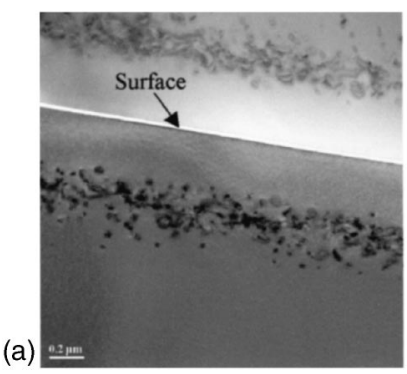

(b)

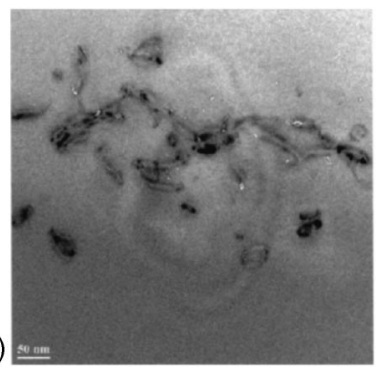

FIG. 6. Cross-section transmission electron micrographs of a sample with a boron marker layer, implanted with $2.3 \times 10^{15} \mathrm{~cm}^{-2}$ fluorine and annealed for $30 \mathrm{~s}$ at $1000{ }^{\circ} \mathrm{C}$ in dry $\mathrm{N}_{2}$; (a) low magnification image; (b) high magnification image. 
TABLE III. Estimation of the fluorine concentration after implant required for the formation of the shallow fluorine peak and the fluorine shoulder obtained from an analysis of the depths at which the fluorine concentration after anneal drops below the critical value of $1 \times 10^{18} \mathrm{~cm}^{-3}$.

\begin{tabular}{cccccc}
\hline \hline & \multicolumn{2}{c}{ Shallow F peak } & & \multicolumn{2}{c}{ F shoulder } \\
\cline { 2 - 3 } $\begin{array}{c}\text { F implant dose } \\
\left(\mathrm{cm}^{-2}\right)\end{array}$ & $\begin{array}{c}\text { Depth at which } \\
\text { F conc. after } \\
\text { anneal is } \\
1 \times 10^{18} \mathrm{~cm}^{-3}(\mu \mathrm{m})\end{array}$ & $\begin{array}{c}\text { F concentration } \\
\text { after implant at the } \\
\text { given depth }\left(\mathrm{cm}^{-3}\right)\end{array}$ & $\begin{array}{c}\text { Depth at which } \\
\text { F conc. after anneal } \\
\text { is } 1 \times 10^{18} \mathrm{~cm}^{-3}(\mu \mathrm{m})\end{array}$ & $\begin{array}{c}\text { F concentration } \\
\text { after implant at the } \\
\text { given depth }\left(\mathrm{cm}^{-3}\right)\end{array}$ \\
\hline $9 \times 10^{14}$ & $\ldots$ & $\ldots$ & 0.28 & $1.5 \times 10^{19}$ \\
$1.4 \times 10^{15}$ & 0.15 & $5.6 \times 10^{18}$ & 0.23 & $1.5 \times 10^{19}$ \\
$2.3 \times 10^{15}$ & 0.07 & $3.6 \times 10^{18}$ & $\cdots$ & $\cdots$ \\
\hline \hline
\end{tabular}

There is considerable evidence in the literature for the formation of vacancy-fluorine clusters. ${ }^{13,17,23-25}$ For example, Shano et al. ${ }^{13}$ proposed the presence $\mathrm{F}-\mathrm{V}_{6}$ clusters on the basis of ab initio calculations and Diebel et al. ${ }^{17,25}$ proposed the presence of $\mathrm{F}-\mathrm{V}_{3}$ clusters. ${ }^{17,25}$ Positron annihilation spectroscopy has also been used to directly show the presence of fluorine vacancy complexes close to the surface. ${ }^{23}$ Our results are consistent with this work, and hence we propose that the shallow fluorine peak is due to the trapping of fluorine at vacancy-fluorine clusters. Support for this conclusion comes from the results in Fig. 5, which show that a fluorine concentration after anneal of $\approx 1 \times 10^{18} \mathrm{~cm}^{-3}$ is needed for the fluorine vacancy clusters to form and for boron thermal diffusion to be reduced. This value is in agreement with the results of Shano et al. ${ }^{13}$ who showed that a minimum fluorine concentration of $1 \times 10^{18} \mathrm{~cm}^{-3}$ was required after anneal to suppress boron transient enhanced diffusion.

A comparison of the SIMS profile in Fig. 4(d) with the TEM micrograph in Fig. 6, shows that the deep fluorine peak correlates with the band of dislocation loops. The deep fluorine peak extends from about 0.28 to $0.70 \mu \mathrm{m}$, which compares with the band of defects in Fig. 6 extending from about 0.29 to $0.73 \mu \mathrm{m}$. Similar dislocation loops have been reported by Wu, Fulks, and Mikkelsen ${ }^{30}$ for a $\mathrm{BF}_{2}^{+}$implant and by $\mathrm{Pi}$, Burrows, and Coleman ${ }^{23}$ for a $\mathrm{F}^{+}$implant. Wu, Fulks, and Mikkelsen reported that the loops were perfect and faulted partial interstitial loops, with sizes ranging from $\approx 20-80 \mathrm{~nm} .{ }^{30}$ Given the similarity between these reported loops and those in Fig. 6, and the location of the deep fluorine peak in the interstitial-rich region of the fluorine damage profile, we propose that the deep fluorine peak is due to fluorine clustering at interstitial dislocation loops.

As discussed in the introduction, several alternative mechanisms have been proposed to explain the effect of fluorine in suppressing the transient enhanced diffusion of boron, including a chemical interaction between boron and fluorine, ${ }^{4,9,11,14,16}$ the presence of vacancy-fluorine clus$\operatorname{ter}^{13,17,18,25}$ and the interaction of fluorine with interstitials. ${ }^{2,4-10,18}$ The possibility of a chemical interaction between boron and fluorine can be discounted, since the shallow fluorine peak is seen whether or not a boron marker layer is present, as shown in Figs. 4(c) and 4(d), indicating that the shallow fluorine peak is not caused by the presence of the boron marker layer. Figure 4 also shows that the deep fluorine peak is present at all $\mathrm{F}^{+}$doses, while Fig. 1 shows that suppression of boron thermal diffusion is only seen for the highest $\mathrm{F}^{+}$dose of $1.4 \times 10^{15} \mathrm{~cm}^{-2}$. Trapping of interstitials at dislocation loops in the deep fluorine peak can therefore also be discounted as an explanation for the effect of fluorine on boron thermal diffusion. The strong correlation between the suppression of boron thermal diffusion and the appearance of the shallow fluorine peak in the vicinity of the boron marker layer at a fluorine implantation dose of 1.4 $\times 10^{15} \mathrm{~cm}^{-2}$ provides clear evidence that this peak is responsible for the suppression of boron thermal diffusion. The presence of vacancy-fluorine clusters in the vicinity of the boron marker layer, as discussed above, would be expected to give an undersaturation of the local interstitial concentration, since any interstitials in the vicinity would be able to recombine and annihilate with vacancies at or near the vacancy-fluorine clusters. Since boron diffusion in silicon is mediated by interstitials, an undersaturation of the interstitial concentration would give rise to a suppression of the boron thermal diffusion.

A comparison of the shapes of the shallow fluorine peaks in Figs. 4(c) and 4(d) shows not only an increase in peak fluorine concentration with $\mathrm{F}^{+}$implantation dose, but also a broadening of the peak. Taking a fluorine concentration after anneal of $1 \times 10^{18} \mathrm{~cm}^{-3}$ as a reference (the concentration required for the shallow peak formation), the shallow fluorine peak extends to within $0.15 \mu \mathrm{m}$ of the surface for a $\mathrm{F}^{+}$dose of $1.4 \times 10^{15} \mathrm{~cm}^{-2}$ and within $0.07 \mu \mathrm{m}$ for a dose of 2.3 $\times 10^{15} \mathrm{~cm}^{-2}$, as shown in Table III. Thus the shallow fluorine peak extends closer to the surface at the higher $\mathrm{F}^{+}$dose. This behavior can be understood if critical fluorine and vacancy concentrations after implant are required for the vacancyfluorine clusters to form. The as-implanted fluorine profiles in Fig. 4 show a rising fluorine concentration with increasing depth in the vicinity of the shallow fluorine peak. In contrast, simulations of vacancy profiles after implant ${ }^{27}$ indicate that the vacancy concentration decreases with increasing depth, which is the opposite trend to the fluorine concentration. In the surface region where the shallow fluorine peak is located, the fluorine concentration is low but the vacancy concentration is high, so the fluorine concentration would be expected to limit the vacancy-fluorine cluster formation. This can explain why the shallow fluorine peak extends towards the surface with increasing $\mathrm{F}^{+}$dose, since the depth at which the fluorine concentration after implant reaches the critical value 
TABLE IV. Estimation of the fluorine concentration after implant required for the formation of the shallow fluorine peak and the fluorine shoulder obtained from analysis of the peak fluorine concentrations in the shallow fluorine peak and fluorine shoulder at different $\mathrm{F}^{+}$implant doses.

\begin{tabular}{|c|c|c|c|c|}
\hline \multirow[b]{2}{*}{ F implant dose $\left(\mathrm{cm}^{-2}\right)$} & \multicolumn{2}{|c|}{ Shallow F peak } & \multicolumn{2}{|c|}{ F shoulder } \\
\hline & $\begin{array}{l}\text { F conc. after } \\
\text { implant at depth } \\
\text { of } 0.16 \mathrm{~nm}\left(\mathrm{~cm}^{-3}\right)\end{array}$ & $\begin{array}{c}\text { Shallow } \\
\text { peak present? }\end{array}$ & $\begin{array}{c}\text { F conc. after } \\
\text { implant at } \\
\text { depth of } 0.29 \mathrm{~nm}\left(\mathrm{~cm}^{-3}\right)\end{array}$ & Shoulder present? \\
\hline $5 \times 10^{14}$ & $2.5 \times 10^{18}$ & & $1.0 \times 10^{19}$ & \\
\hline $9 \times 10^{14}$ & $4.0 \times 10^{18}$ & & $1.7 \times 10^{19}$ & $レ$ \\
\hline $1.4 \times 10^{15}$ & $6.6 \times 10^{18}$ & レ & $2.5 \times 10^{19}$ & $\boldsymbol{\nu}$ \\
\hline $2.3 \times 10^{15}$ & $11 \times 10^{18}$ & レ & $4.6 \times 10^{19}$ & レ \\
\hline
\end{tabular}

required for cluster formation (value estimated below) lies closer to the surface at higher fluorine doses.

The critical fluorine concentration after implant required for vacancy-fluorine cluster formation can be estimated either from the point on the shallow fluorine peak at which the fluorine concentration drops below $1 \times 10^{18} \mathrm{~cm}^{-3}$ or from the as-implanted fluorine concentration in the vicinity of the shallow fluorine peak at the critical $\mathrm{F}^{+}$implant dose. Values of critical fluorine concentration after implant are summarized in Table III for the first method and in Table IV for the second method. Table III shows a critical fluorine concentration after implant of $5.6 \times 10^{18} \mathrm{~cm}^{-3}$ for a $\mathrm{F}^{+}$dose of 1.4 $\times 10^{15} \mathrm{~cm}^{-2}$ and of $3.6 \times 10^{18} \mathrm{~cm}^{-3}$ for a $\mathrm{F}^{+}$dose of 2.3 $\times 10^{15} \mathrm{~cm}^{-2}$. For comparison, Table IV shows that the shallow fluorine peak appears at a critical $\mathrm{F}^{+}$implant dose between $9 \times 10^{14}$ and $1.4 \times 10^{15} \mathrm{~cm}^{-2}$, which gives a critical fluorine concentration after implant between $4.0 \times 10^{18}$ and $6.6 \times 10^{18} \mathrm{~cm}^{-3}$. These values in Table IV are of the same order as those in Table III, which gives some confidence in their validity. From this data it can therefore be concluded that the critical fluorine concentration after implant for the formation of the vacancy-fluorine clusters in the shallow fluorine peak is in the range $3.6 \times 10^{18}-6.6 \times 10^{18} \mathrm{~cm}^{-3}$.

Finally, it is interesting to speculate on the origin of the fluorine shoulder, which is present at a depth of $0.22-0.28 \mu \mathrm{m}$. This is equivalent to a depth of $0.52-0.67 R_{p}$, which indicates that the shoulder is in the vacancy-rich region of the damage profile. The TEM results in Fig. 6 show that there are no dislocation loops at this depth, and hence the shoulder is not due to trapping of fluorine at dislocation loops. Furthermore, the results in Fig. 5 show that the variation of peak fluorine concentration in the shoulder with implanted fluorine dose follows a similar trend to that seen in the shallow fluorine peak, though with the critical fluorine dose shifted to a lower value. These considerations point to the conclusion that the shoulder is due to some kind of vacancy-fluorine cluster. Following the two approaches described above for estimating the critical $\mathrm{F}^{+}$ dose after implant, Table III gives a value of 1.5 $\times 10^{19} \mathrm{~cm}^{-3}$ at a F dose of $9 \times 10^{14}$ and $1.5 \times 10^{19} \mathrm{~cm}^{-3}$ at a $\mathrm{F}^{+}$dose of $1.4 \times 10^{15} \mathrm{~cm}^{-2}$, while Table IV gives a value in the range $1.0-1.7 \times 10^{19} \mathrm{~cm}^{-3}$. These two approaches are again giving values of the same order, and all fall within a range of $1.0-1.7 \times 10^{19} \mathrm{~cm}^{-3}$. This range is different than that obtained for the shallow fluorine peak $\left(3.6 \times 10^{18}-6.6\right.$ $\times 10^{18} \mathrm{~cm}^{-3}$ ), which suggests that the fluorine shoulder may be due to a different type of vacancy-fluorine cluster than the shallow fluorine peak. Since the shoulder is in a region where the fluorine concentration is high and the vacancy concentration is low $^{27}$ after implant, we speculate that the clusters in this region may be fluorine rich. Similarly, since the shallow fluorine peak is in a region where the fluorine concentration is low and the vacancy concentration high ${ }^{27}$ after implant, we speculate that the clusters in this region may be vacancy rich. Support for this hypothesis comes from reports in the literature which showed that for a $0.5 \mathrm{MeV}$, $5 \times 10^{15} \mathrm{~cm}^{-2} \mathrm{~F}^{+}$implant, V-dominated V-F complexes were formed closer to the surface and, F-dominated V-F complexes were formed deeper closer to the implantation range. ${ }^{23}$ Further work is needed to confirm this hypothesis.

\section{CONCLUSIONS}

A study has been carried out of the effect of fluorine implants with doses in the range $5 \times 10^{14}-2.3 \times 10^{15} \mathrm{~cm}^{-2}$ on the thermal diffusion of boron marker layers in silicon. For $\mathrm{F}^{+}$doses of $1.4 \times 10^{15}$ and $2.3 \times 10^{15} \mathrm{~cm}^{-2}$ the fluorine significantly reduces the boron thermal diffusion coefficient by factors of 1.9 and 37, respectively. This reduction of boron thermal diffusion correlates with the appearance of a shallow fluorine peak (depth $=0.07-0.22 \mu \mathrm{m})$ in the SIMS profile at a $\mathrm{F}^{+}$dose of $1.4 \times 10^{15} \mathrm{~cm}^{-2}$. This peak is present in samples with and without the boron marker layer and hence is not due to a chemical interaction between the fluorine and boron. The results suggest that the shallow fluorine peak is due to vacancy-fluorine clusters and that the reduction in boron thermal diffusion is due to a suppression of the excess interstitial concentration in the vicinity of the boron marker layer due to the presence of the clusters. Analysis of the SIMS profiles indicates that a fluorine concentration after implant in the range $3.6-6.6 \times 10^{18} \mathrm{~cm}^{-3}$ is needed for the vacancy-fluorine clusters to form.

\section{ACKNOWLEDGMENT}

The authors would like to acknowledge the Engineering and Physical Sciences Research Council for funding this work.

${ }^{1}$ R. G. Wilson, J. Appl. Phys. 54, 6879 (1983).

${ }^{2}$ K. Ohyu, T. Itoga, and N. Natsuaki, Jpn. J. Appl. Phys., Part 1 29, 457 (1990). 
${ }^{3}$ D. Fan, J. M. Parks, and R. J. Jaccodine, Appl. Phys. Lett. 59, 1212 (1991).

${ }^{4}$ L. Y. Krasnobaev, N. M. Omelyanovskaya, and V. V. Makarov, J. Appl. Phys. 74, 6020 (1993).

${ }^{5}$ T. H. Huang, H. Kinoshita, and D. L. Kwong, Appl. Phys. Lett. 65, 1829 (1994).

${ }^{6}$ H. -H. Vuong et al., J. Appl. Phys. 77, 3056 (1995).

${ }^{7}$ D. F. Downey, J. W. Chow, E. Ishida, and K. S. Jones, Appl. Phys. Lett. 73, 1263 (1998).

${ }^{8}$ Y.-J. Park and J-J Kim, J. Appl. Phys. 85, 803 (1999).

${ }^{9}$ J. Liu, D. F. Downey, K. S. Jones, and E. Ishida, Proceedings of the International Conference on Ion Implantation Technology, Kyoto, Japan, 22-26 June 1998, edited by J. Matsuo, G. Takaoka, and I. Yamada (IEEE,Piscataway, NJ, 1999), Vol. 2, p. 951.

${ }^{10}$ E. Ishida, D. F. Downey, K. S. Jones, and J. Liu, Proceedings of the International Conference on Ion Implantation Technology, Kyoto, Japan, 22-26 June 1998, edited by J. Matsuo, G. Takaoka, and I. Yamada (IEEE, Piscataway, NJ, 1999), Vol. 2, p. 909.

${ }^{11}$ L. S. Robertson, P. N. Warnes, K. S. Jones, S. K. Earles, M. E. Law, D. F. Downey, S. Falk, and J. Liu, Mater. Res. Soc. Symp. Proc. 610, B4.2.1 (2000).

${ }^{12}$ N. Ohno, T. Hara, Y. Matsunaga, M. I. Current, and M. Inoue, Mater. Sci. Semicond. Process. 3, 221 (2000).

${ }^{13}$ T. S. Shano, R. Kim, T. Hirose, Y. Furuta, H. Tsuji, M. Furushashi, and K. Taniguchi, Tech. Dig. - Int. Electron Devices Meet. 37, 41 (2001).

${ }^{14}$ A. Mokhberi, R. Kasnavi, P. B. Griffin, and J. D. Plummer, Appl. Phys. Lett. 80, 3530 (2002).

${ }^{15}$ J. M. Jacques, L. S. Robertson, and K. S. Jones, Mater. Res. Soc. Symp.
Proc. 717, C461 (2002).

${ }^{16}$ A. Dusch, J. Marcon, K. Masmoudi, K. Ketata, F. Olivie, M. Benzohra, and M. Ketata, Nucl. Instrum. Methods Phys. Res. B 186, 360 (2002).

${ }^{17}$ M. Diebel, S. Charkravarthi, C. F. Machala, S. Ekbote, A. Jain, and S. T. Dunham, Mater. Res. Soc. Symp. Proc. 765, D6.15 (2003).

${ }^{18}$ H. A. W. El Mubarek and P. Ashburn, Appl. Phys. Lett. 83, 4134 (2003).

${ }^{19}$ K. Liu, J. Wu, J. Chen, and A. Jain, IEEE Electron Device Lett. 24, 180 (2003).

${ }^{20}$ H. Fukutome, Y. Momiyama, H. Nakao, T. Aoyama, and H. Arimoto, Tech. Dig. - Int. Electron Devices Meet. 2003, 485.

${ }^{21}$ P. Ashburn, Design and Realization of Bipolar Transistors (Wiley, New York, 1988).

${ }^{22}$ D. J. Eaglesham, P. A. Stolk, H.-J. Gossmann, and J. M. Poate, Appl. Phys. Lett. 65, 2305 (1994).

${ }^{23}$ X. D. Pi, C. P. Burrows, and P. G. Coleman, Phys. Rev. Lett. 90, 155901 (2003).

${ }^{24}$ R. R. Robinson and M. E. Law, Tech. Dig. - Int. Electron Devices Meet. 2002, 883.

${ }^{25}$ M. Diebel and S. T. Dunham, Mater. Res. Soc. Symp. Proc. 717, C4.5.1 (2002).

${ }^{26}$ S. Tian, Nucl. Instrum. Methods Phys. Res. B 215, 403 (2004).

${ }^{27}$ M. D. Giles, J. Electrochem. Soc. 138, 1160 (1991).

${ }^{28}$ A. Sultan, S. Banerjee, S. List, and V. McNeil, J. Appl. Phys. 83, 8046 (1998).

${ }^{29}$ S.-P. Jeng, T.-P. Ma, R. Canteri, M. Anderle, and G. W. Rubloff, Appl. Phys. Lett. 61, 1310 (1992).

${ }^{30}$ I-W. Wu, R. T. Fulks, and J. C. Mikkelsen Jr., J. Appl. Phys. 60, 2422 (1986). 